\title{
MOBILE LASER SCANNING ELEVATION DATA ACCURACY IN CLOSED AND PARTIALLY OPEN SKY AREA
}

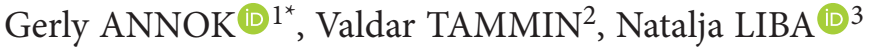 \\ ${ }^{1} 100$ Aakrit Ltd, Tallinn, Estonia \\ ${ }^{2}$ Bureau of Geodesy and Engineering Geology Ltd (REIB Ltd), Tallinn, Estonia \\ ${ }^{3}$ Institute of Forestry and Rural Engineering, Estonian University of Life Sciences, Tartu, Estonia
}

Received 03 February 2020; accepted 12 March 2021

\begin{abstract}
Mobile laser scanning is being used more often in Estonia and abroad to obtain geospatial information. As the system is still new and being upgraded, different methods are being used to find out how accurately the mobile laser scanner can measure in different conditions. In this article the mobile laser scanner accuracy is being examined depending on surrounding environment and the importance of postprocessing. Mobile laser scanning elevation data accuracy obtained in difficult conditions is being assessed. Difficult conditions are considered locations where there are tall objects that interrupt the satellite signals' trajectory to the receiver. To determine the elevation accuracy of mobile laser scanner data, coordinates with the raw broadcast and final ephemerides with the combination of the GNSS receivers' data that were installed in ideal and not ideal environmental conditions were computed.

As a result of the study, the error of the elevation data in the first polygon, situated in difficult conditions was $7 \mathrm{~mm}$ when the Kunda reference station data was used with raw broadcast and final ephemerides. Error in the second polygon was accordingly $17 \mathrm{~mm}$ and $19 \mathrm{~mm}$. When calculations were conducted using raw broadcast ephemerides in a base station in an imperfect environment, the error in the first polygon was $103 \mathrm{~mm}$ and in the second $75 \mathrm{~mm}$. When the precise ephemerides were added to base station data, the error in the first polygon was $6 \mathrm{~mm}$ and in the second $21 \mathrm{~mm}$. From the study results, it could be concluded that the mobile laser scanning system measures within $2 \mathrm{~cm}$ accuracy even in a complicated environment.
\end{abstract}

Keywords: mobile laser scanning, point cloud, kinematic measuring, elevation accuracy.

\section{Introduction}

Mobile laser scanning is the kinematic method used to obtain the georeferenced data in the environment, while using a laser scanner, GNSS positioning devices, an inertial measurement unit, inertial navigation systems and frequently including a distance measurement instrument and cameras. MLS is especially useful for measurements of linear objects such as roads, power lines and city streets. MLS data is obtained from the environment safely, quickly and also accurately when using post-processing.

The hybrid mobile laser scanning system Riegl VMZ/VZ-400 which measure in static and kinematic mode was used in this study. The system contains laser scanner Riegl VZ-400 that measures up to 122000 points and three-to- 120 lines in a second. The accuracy of the laser scanner has been assessed to be $5 \mathrm{~mm}$ and measurement range from $1.5 \mathrm{~m}$ up to $600 \mathrm{~m}$. Riegl VZ-400 scan angle is $100^{\circ}\left(+60^{\circ} \%-40^{\circ}\right)$ (Riegl, 2014). The laser scanner can be installed on the platform horizontally to measure roads and vertically for buildings. Laser scanner VZ-400 uses the time-of-flight method which is based on the speed of light. The laser scanner transmits very short laser impulses and measures the time of the reflected laser impulse. When the speed of light is known, the accurate distance of the object can be calculated (Formula 1).

$$
S=\frac{c \times \Delta t}{2}
$$

where $c$ is the speed of light in vacuum $299792458 \mathrm{~m} / \mathrm{s}$; $\Delta t$ is the time difference of transmitted and reflected laser impulse.

The Riegl VMZ system includes two Trimble Zephyr model 2 GNSS antennas that measure the vehicles' location and direction. Two antennas relative location vector measurement is important for inertial measurement unit (IMU) calibration and accurate direction azimuth (Applanix Corporation, 2014, p. 4). The antennas are suitable in

*Corresponding author. E-mail: gerlyannok@hotmail.com 
an environment with vibrations and mechanical shocks, therefore, it is perfect for mobile laser scanner systems. The antennas are connected with a Trimble BD982 receiver with vertical accuracy of $15 \mathrm{~mm}+1 \mathrm{ppm}$ (Trimble, 2010). The Riegl VMZ system antennas, IMU and DMI reference point on the vehicle are shown in Figure 1.

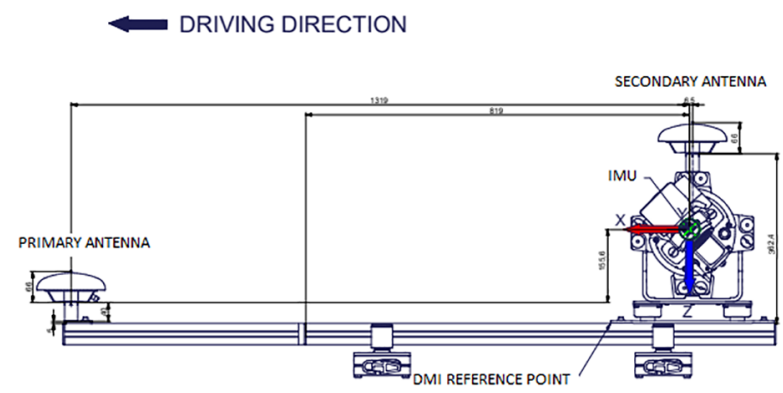

Figure 1. Riegl VMZ system two antennas, IMU placement and DMI reference point on the vehicle (Hybrid Mobile Laser Mapping System, 2014, p. 57)

The Riegl VMZ also contains an IMU that measures and fixes a body's force, acceleration and angular heading using an acceleration gauge and gyroscopes (Puente et al., 2011, p. 2; Løvås, 2017, p. 7). The IMU continuously provides the vehicle's accurate position and direction in threedimensional space (Narayana, 2011, p. 64). Together, the IMU and GNSS provide the locational data with accuracy of $20-50 \mathrm{~mm}$, if there aren't GNSS outages, DMI is being used and data is being post-processed with base station data (Hybrid Mobile Laser Mapping System, 2014).

To gather accurate data, the DMI (Distance Measurement Instrument) is attached to the vehicle's wheel. DMI measures the vehicle's distance counting the rotation of the vehicle's wheel. Before using the DMI, the wheel's rotation in one meter is calculated (Formula 2), to find the vehicle's wheel DMI coefficient.

$$
s=\frac{4 n}{d \pi},
$$

where $n$ is the number that the sensor counts in one meter, $d$ is the wheel's diameter (Hybrid Mobile Laser Mapping System, 2014, p. 49).
Riegl VMZ/VZ-400 system elevation data accuracy has been previously assessed by Putnik (2018), taking measurements in varying locations (below the viaduct, in a tunnel and crossroad) and on different road covers (asphalt and concrete road). Szulwic and Tysiąc (2017) mapped cracks in the road using the same system and, a year later (Szulwic \& Tysiąc, 2018), conducted measurements on the sea, installing the MLS on a ship. Annok (2017) assessed elevation data accuracy on the road that passed through forest and open sky area.

\section{Materials and methods}

Mobile laser scanning was conducted in North Estonia in the city of Kunda in 2018, using mobile laser scanner system Riegl VMZ/VZ-400 (Figure 2).

Mobile laser scanning was conducted at the same time with the RTK GNSS measurements, using the Trimble R8s: the vertical root mean square error is $15 \mathrm{~mm}+1 \mathrm{ppm}$ (Trimble, 2017). The measurements were taken at the same time to assure that all GNSS receivers in the study used identical satellites. Measurements were conducted on two geodetical asphalt nails. The asphalt nails were levelled in collaboration with Republic of Estonia institution Maa-amet and private limited companies Metricus, Hades Geodeesia and REIB. Also installed near the measurement site was GNSS receiver Sokkia GCX2 (referred to as base station) for post-processing and further analyses. The GNSS receiver provided continuous measurements while the mobile laser scanning was conducted. Sokkia GCX2 receiver provides elevation data accuracy $5 \mathrm{~mm}+0.5 \mathrm{~mm}$ ppm in static mode (Topcon, 2015). Sokkia and Trimble receivers used the satellites from the 15-degree angle; the receiver on the vehicle used satellites from the 7.5-degrees angle.

To assess accuracy of the mobile laser scanner elevation data, two polygons located in difficult conditions for the scanner were chosen. The first polygon was surrounded by high trees on both sides of the road. The second polygon had high trees in the south-east direction; the north-west direction was more open, but there were high trees and a building a couple meters away from the research point.

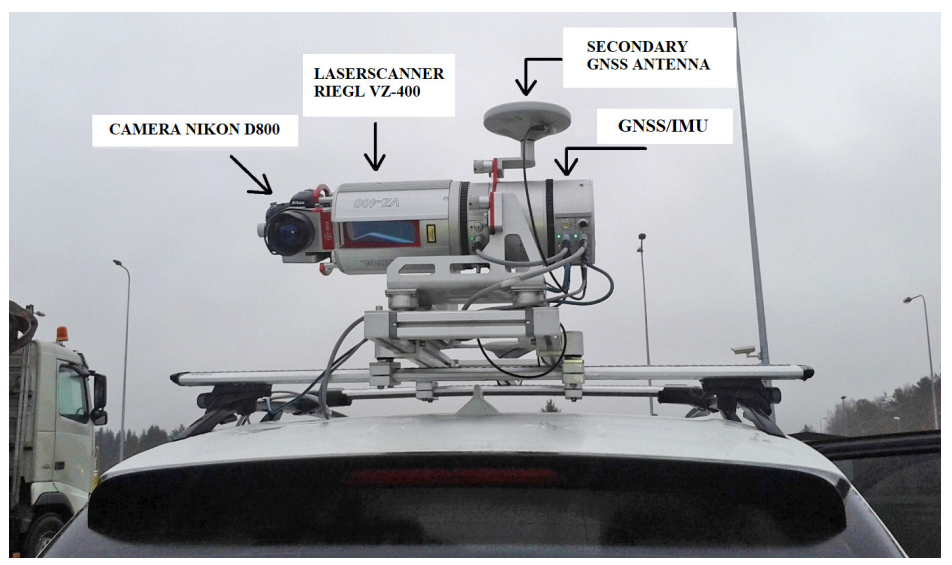

Figure 2. Installed onto the roof of the vehicle are a horizontally terrestrial laser scanner Riegl VZ-400, IMU/GNSS, secondary GNSS antenna and camera Nikon D800 (Kokamägi 2016 referred to in Annok, 2017) 


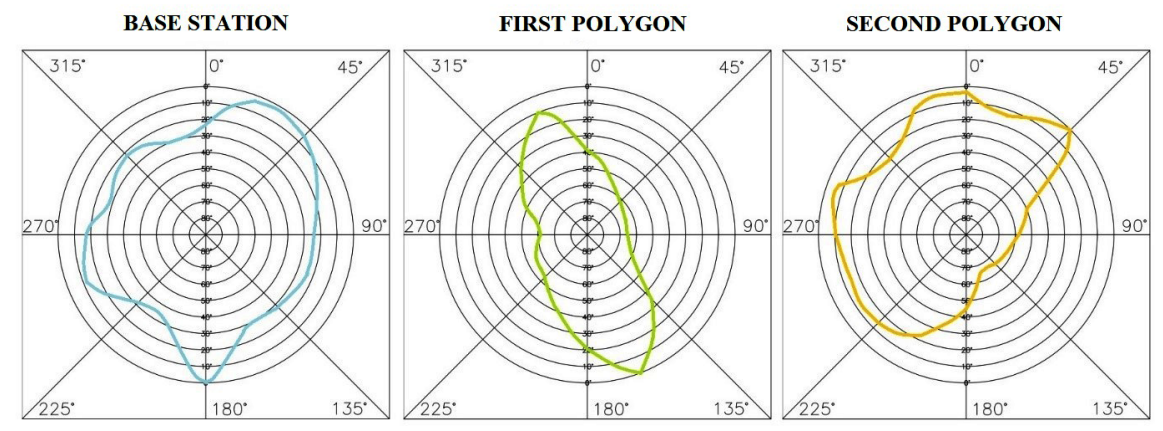

Figure 3. Base station, I and II polygon points horizon openness, where the zero conforms with geographical north direction (Annok, 2019)

Both polygons and base station receiver horizon openness are shown on Figure 3.

In addition to the base station set up near the measurement site, the Kunda reference station data was also used. The Kunda reference station is administered by Estonian private limited company Geosoft and it densifies Trimble VRS Now GNSS network in Estonia. The Kunda reference station, located on a high-rise building about $1.5 \mathrm{~km}$ away from the polygons provides ideal conditions for GNSS measurements. Post-processed kinematic (PPK) data collecting method was used in the study; accurate location data for MLS is calculated after the measurements in the control system (computer) by using the base station data. Post-processing avoids data or initialization mistakes, which can evolve from radio link failure. When using PPK, trajectory calculations can be made in forward and backward direction to assure an accurate result (Geavis, 2018). The PPK method requires the base station to be close to the mobile station (MLS platform), usually within a $5-\mathrm{km}$ radius, which is important when applying corrections (Cox, 2016, p. 3). In this study both the Kunda reference station and base station were close enough to the measurement site.

\section{Data processing}

Data processing consisted of four phases. Firstly, the vector calculation was made to determine coordinates for the base station installed near the measurement site. Calculations were made using the program Magnet Tools (version 4.3.0), where coordinates were found in the least squares method. The least squares method principle is based on minimization of the sum of the squares of the residuals made in the results of every single equation (Soe, 2016, p. 27). Requirement is shown in Formula 3:

$$
\sum v^{2}=\min ,
$$

where $\Sigma v^{2}$ is the sum of the squares of the corrections.

Secondly, the trajectory was computed in program Applanix POSPac MMS 7.2. Four different schemes were used in the computation. For the trajectory computation, the following were used:

- Kunda reference station coordinates, MLS data and

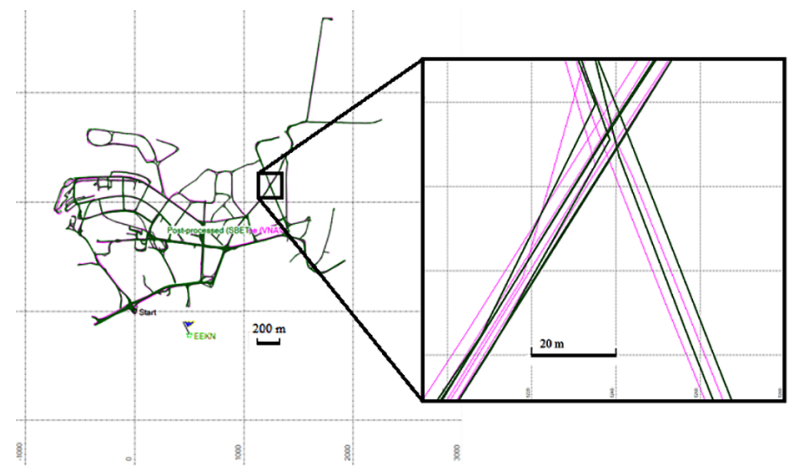

Figure 4. The trajectory computed with Kunda reference station (EEKN) and excerpt of the area where research polygons are located. Purple shows the primal trajectory and green the corrected trajectory (Annok, 2019)

raw broadcast satellite orbits ephemerides.

- Kunda reference station coordinates, MLS data and final precise satellite orbits ephemerides.

- Base station coordinates, MLS data and raw broadcast satellite orbits ephemerides.

- Base station coordinates, MLS data and final precise satellite orbits ephemerides.

Final precise satellite orbits ephemerides were downloaded from the International GNSS Service website. The data processing included final precise ephemerides, the accuracy of which has been assessed to be about $2.5 \mathrm{~cm}$ in GPS and about $3 \mathrm{~cm}$ in GLONASS constellation (International GNSS Service [IGS], 2019). Primal and corrected final trajectories are shown on Figure 4.

The fourth step was the point cloud calculation made using program RiProcess. Coordinated point clouds were calculated on the trajectory and noise was removed. After the noise removal, the point clouds were smoothed and combined. In this study eight point clouds (two from first polygon, six from second polygon) were combined. Data was taken before and after the adjustment.

\section{Results and discussion}

The trajectories measured outside are the base of the coordinates gained from point clouds. The study analysis provided the estimated elevation error of smoothed trajectories. Figure 5 shows root mean squares of the smoothed 
trajectories when initially using Kunda reference station and MLS data and, following that, when the final precise ephemerides were added. The third computation shows the trajectory with base station and MLS data; final precise ephemerides were added. Figure shows only the moments when MLS and RTK GNSS measurements matched. The whole trajectory was used in the primal calculation of the point clouds.

When using the different schemes, the biggest estimated elevation error was in the second measurement of the first polygons. When Kunda reference station was used, the errors were up to $20 \mathrm{~mm}$; when the base station was used the RMS was up to $31 \mathrm{~mm}$. The use of final precise ephemerides did not affect the trajectory data which was calculated with the base station data. The accuracy of the trajectory was mostly affected when Kunda reference station and the final precise ephemerides were used. The five measurements demonstrate the improvement of RMS or a similar result when only reference station data was used. Most of the trajectory estimated elevation RMS stayed within two centimeters.

After that, the point clouds were added onto the trajectory data; that determined how much the not-smoothed point cloud differs from levelled heights in two polygons (Figure 6). The not-smoothed point cloud was compared with levelled heights to determine the error to an individual point. Values were found in four different schemes, mentioned before.

The points which differed mostly from the levelled height were those which were computed with the base station installed near to the measurement area and when final precise ephemerides were not used. Higher elevation

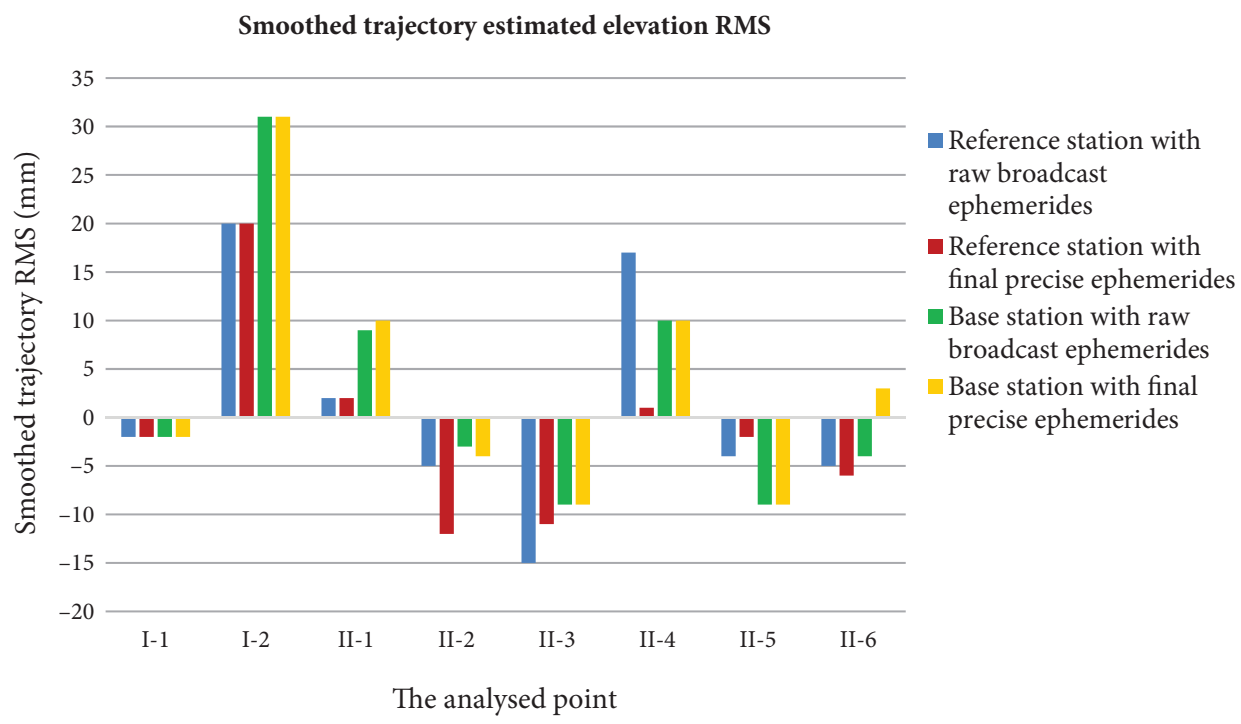

Figure 5. Smoothed trajectory estimated elevation RMS in analysed points, using four different schemes in trajectory calculation (Annok, 2019)

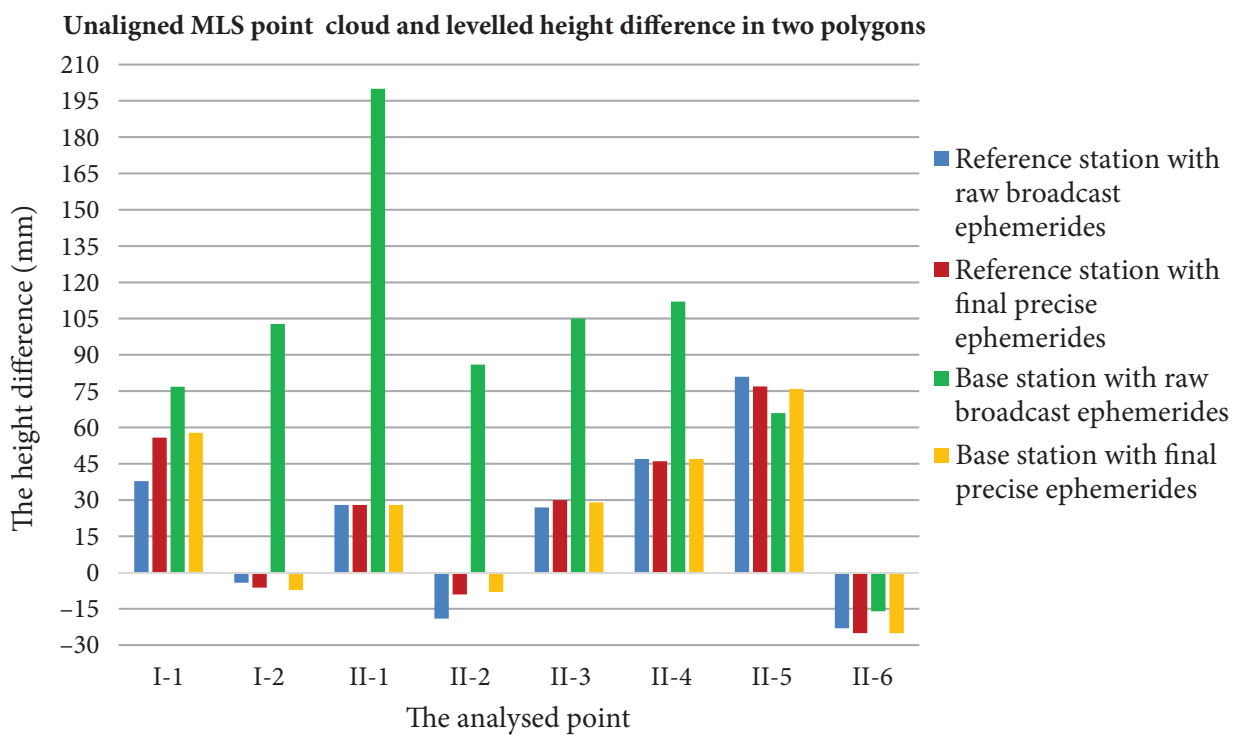

Figure 6. Unaligned MLS point cloud and levelled height difference in two polygons when four different computation schemes were used (Annok, 2019) 


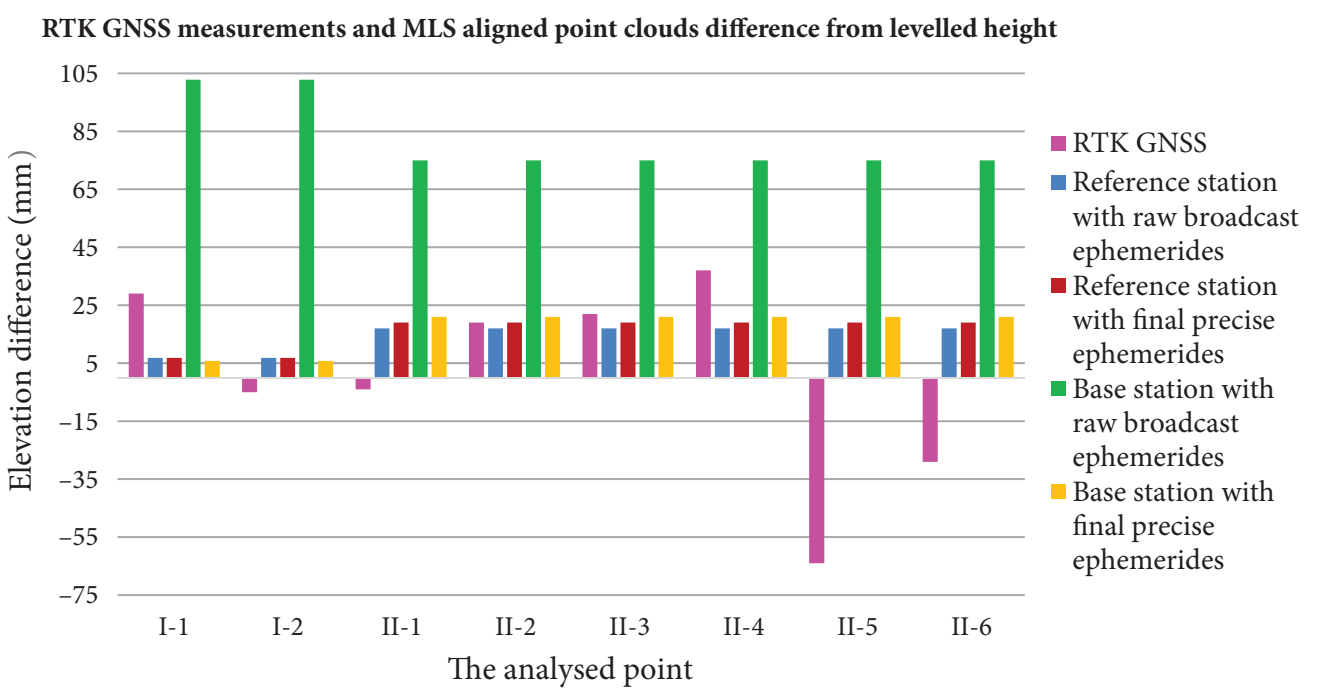

Figure 7. RTK GNSS and aligned MLS point cloud data calculated with four different schemes difference from levelled height (Annok, 2019)

data was gained in the first polygons' second measurement, and the second polygons' second and sixth measurements with MLS compared with levelled height. When the base station was used, the first two measurements previously mentioned had lower elevation height compared with levelled height. When Kunda reference station with raw broadcast and final precise ephemerides and the base station with final precise ephemerides were used in calculation the similar height data was gained. It shows that reference and base stations found in both ideal and not ideal locations can be used in calculations. Even though the stability in data is added when final precise ephemerides are used, high accuracy still might not be provided in unaligned point clouds.

After the alignment (Figure 7), it was found that the MLS elevation data that differed the most from the levelled height was that which was computed with the base station and raw broadcast ephemerides. In the first polygon the difference was $103 \mathrm{~mm}$ and in second $57 \mathrm{~mm}$. But results indicate that when the final precise ephemerides were added, the error was similar to the data that was computed with Kunda reference station. With other schemes the first polygon error from the levelled height was up to $7 \mathrm{~mm}$. In the second polygon, the elevation error was below $25 \mathrm{~mm}$, and the differences between the three calculation schemes were four millimeters.

Comparing the results calculated with Kunda reference station, it can be seen that if raw broadcast ephemerides were used, the second polygon error was smaller than when final ephemerides were used. The difference remains only two millimeters. As a result of the point cloud adjustment it can be stated that the worst results can be gained with MLS when the trajectory calculation includes data from base station that is not in an ideal environment and the final precise ephemerides are not added. Other calculation schemes provide acceptable height accuracy for the geodetical works that require higher accuracy such as pavement, well cap or other similar objects.

When RTK GNSS and MLS smoothed point cloud data is compared with levelled height, it can be seen that RTK GNSS data is very unstable. The RTK GNSS difference from levelled height stays in the range of $-64 \mathrm{~mm}$ to $37 \mathrm{~mm}$. The biggest difference was in the second polygon's fifth measurement. Half of the RTK GNSS measurements were taken in an anticlockwise direction compared with the MLS data. In six measurements of eight has RTK GNSS measured more inaccurately than MLS (except the heights calculated with base station and raw broadcast ephemerides), showing that when only RTK GNSS measurements are taken, results gathered are not as accurate as those with the MLS that uses additional systems such as DMI and IMU.

\section{Conclusions}

The research results indicate that in a difficult environment where objects reduce the horizon and visibility between the mobile laser scanning system and satellites are minimal, the reference station in ideal environmental conditions should be used in the trajectory calculations. When using a base station in a not ideal environment, the final precise ephemerides should be added to the trajectory computation. When using a reference station located in ideal environmental conditions, both the raw broadcast and the final precise ephemerides can be used to gain accurate height data.

The results showed the instability of RTK GNSS measurements. RTK GNSS measurements were conducted at the same time with mobile laser scanning to find out if the errors are similar. The assumption was that both systems use the same satellites even when RTK GNSS used more. The results showed that even though the main component for MLS to get the geospatial data is the GNSS receiver, the other systems can assure the accurate location data. 
The RTK GNSS receiver alone, cannot provide it.

\section{References}

Annok, G. (2017). Mobiilse laserskaneerimise kõrguslik täpsus metsa ja lageda ala korral [Mobile laser scanning elevation data accuracy in forest and open sky areas] [Bachelor's thesis]. Estonian University of Life Sciences Institute of Forestry and Rural Engineering, Tartu, Estonia.

http://dspace.emu.ee/xmlui/bitstream/handle/10492/3261/ Annok_Gerly_BA2017.pdf?sequence=1\&isAllowed=y

Annok, G. (2019). Mobiilse laserskaneerimise kõrguslik täpsus kinnise ja osaliselt avatud taevalaotuse korral [Mobile laser scanning elevation data accuracy in closed and partially open sky area] [Master's thesis]. Estonian University of Life Sciences Institute of Forestry and Rural Engineering, Tartu, Estonia.

Applanix Corporation. (2014). POSPac MMS GNSS-Inertial Tools user guide. Richmond Hill, ON, Canada.

Cox, C. (2016). Mobile Mapping System: a buyer's guide. https://slidelegend.com/queue/mobile-mapping-systems-3dlaser-mapping_59b78bfd1723ddf2725f174c.html

Geavis. (2018). What are the characteristics and differences between RTK and PPK drone?

https://www.geavis.si/en/2018/03/characteristics-differencesrtk-and-ppk-drone/

Hybrid Mobile Laser Mapping System. (2014). Riegl VMZ. http://www.riegl.com/nc/products/mobile-scanning/produktdetail/product/scanner/44/

International GNSS Service. (2019). Products. http://www.igs.org/products

Løvås, M. (2017). Increasing the accuracy of positioning in Mobile Mapping Systems [Master's thesis]. Norwegian University of Science and Technology, Trondheim, Norway.

Narayana, K. (2011). Solutions for the localization of Mobile
Mapping Systems in structures environments [Doctor's thesis]. MINES ParisTech, Paris Institute of Technology, Paris, France.

Puente, I., Gonzalez-Jorge, H., Arias, P., \& Armesto, J. (2011). Land-based mobile laser scanning systems: a review. Spain.

Putnik, M. (2018). Mobiilse laserskaneerimise tehnoloogia rakendamine teekatendite mõõdistamisel [Application of mobile laser scanning technology for surveying road surfaces]. Geodeet, (48), 11-22.

Riegl. (2014). Riegl VZ-400 specification. http://www.riegl.com/ uploads/tx_pxpriegldownloads/10_DataSheet_VZ-400_201706-14.pdf

Soe, H. (2016). Käikude mõõtmine erinevate meetoditega ja tasandusarvutused tavameetodiga ning range tasandamisega [Transverse surveying procedure with various methods and alignment calculations using the conventional method and strict alignment] [Thesis]. Tallinn University of Applied Sciences, Institute of Construction.

Szulwic, J., \& Tysiąc, P. (2017). Searching for road deformations using mobile laser scanning. MATEC Web of Conferences, 122, 1-7. https://doi.org/10.1051/matecconf/201712204004

Szulwic, J., \& Tysiąc, P. (2018). Mobile laser scanning calibration on a marine platform. Polish Maritime Research, 25, 159-165. https://doi.org/10.2478/pomr-2018-0037

Topcon. (2015). Sokkia GCX2 specification. https://www.topcon. co.jp/en/positioning/sokkia/products/pdf/GCX2_E.pdf

Trimble. (2010). Trimble BD982 specification. http://trl.trimble. com/docushare/dsweb/Get/Document-867958/

Trimble. (2017). Trimble R8s specification. https://geospatial. trimble.com/sites/default/files/2019-03/Datasheet\%20-\%20 Trimble\%20R8s\%20GNSS\%20System \%20-\%20English\%20 A4\%20-\%20Screen.pdf 